\title{
La Calzada México-Tacuba: retos en la regeneración y reactivación de un camino histórico
}

Gerardo A. Hernández Septién | Dpto. de Arquitectura, Urbanismo e Ingeniería Civil, Universidad Iberoamericana Ciudad de México

URL de la contribución <www.iaph.es/revistaph/index.php/revistaph/article/view/4943>

\section{RESUMEN}

La antigua calzada México-Tacuba se encuentra en la Ciudad de México, capital del país al que dio nombre. Creada en un entorno lacustre en el siglo XIV, esta avenida de casi $10 \mathrm{~km}$ de longitud es considerada la vía más antigua del continente americano. Por ella han desfilado importantes acontecimientos de la historia nacional, de los cuales aún hay algunos testimonios tangibles. El presente artículo pretende hablar de la importancia histórica y urbana de la calzada México-Tacuba, como una vía viva con un gran potencial como detonador del desarrollo urbano, cultural y turístico, pero que, por desgracia, ha visto mermada sus cualidades espaciales y sus valores tangibles e intangibles, a manos de la falta de regulación y con un entorno conflictivo y hostil en casi toda su trayectoria. El paisaje urbano histórico de la calzada, unido a la dinámica de sus barrios aledaños, debe contar el día de hoy con políticas públicas y privadas que permeen a la sociedad en conjunto para que se dé, de manera continuada y sostenible, su rescate y puesta en valor. Estos temas también se analizan en el presente artículo.

\section{Palabras clave}

Calzadas | Ciudad de México | Conservación (Patrimonio) | México | Paisaje urbano histórico | Periodo prehispánico | Tacuba | 


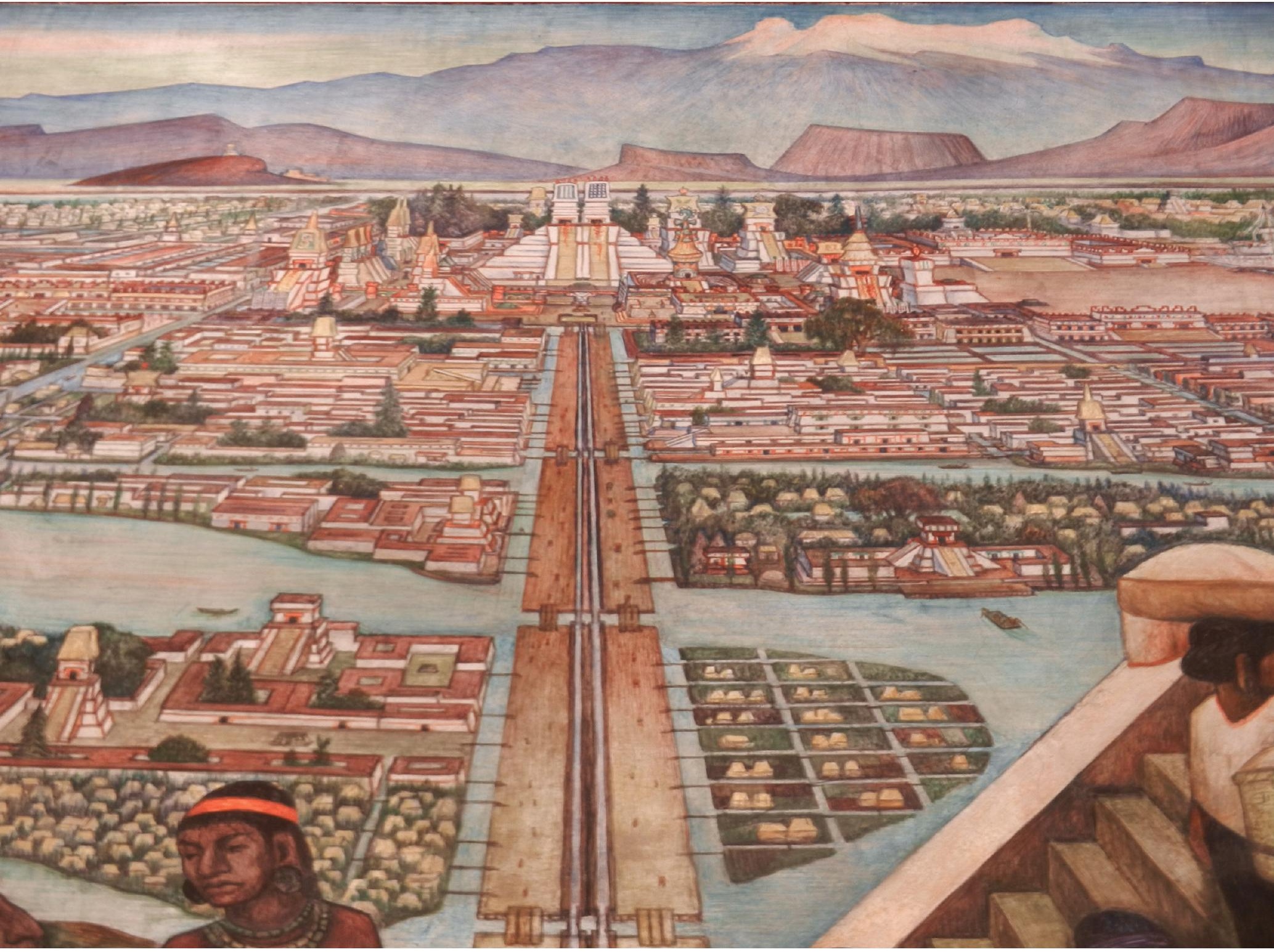

Recreación de México-Tenochtitlan durante la época prehispánica con la Calzada México-Tacuba en primer plano | foto Travis 


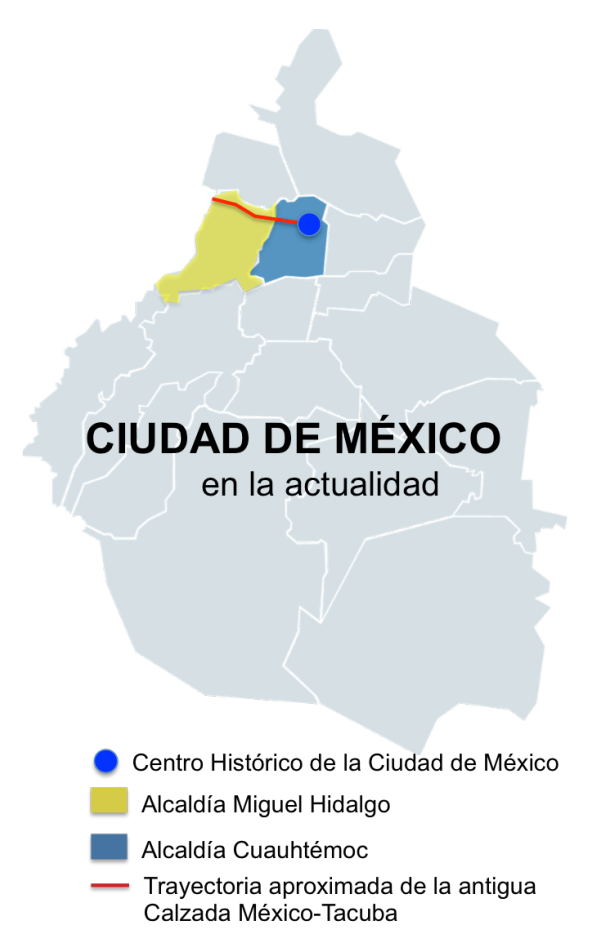

Ubicación de la antigua Calzada México-Tacuba en la actualidad
México-Tacuba es el nombre de una antigua calzada de origen prehispánico de casi $10 \mathrm{~km}$ de extensión que conecta al centro histórico de la Ciudad de México con la antigua zona de Tacuba, al poniente de la capital mexicana, y cuyos tramos en la actualidad, en el sentido oriente-poniente, reciben diferentes nombres: calle República de Guatemala, calle de Tacuba, Avenida Hidalgo, Puente de Alvarado, Ribera de San Cosme, dentro de la alcaldía Cuauhtémoc; y Calzada México-Tacuba (su nombre original), dentro de la alcaldía Miguel Hidalgo, entre el Circuito Interior Melchor Ocampo y la Avenida Ingenieros Militares.

Esta larga vía, a manera de "columna vertebral", aglutina a su alrededor diversos barrios pertenecientes a las dos alcaldías capitalinas antes mencionadas. La realidad de todo su recorrido es contrastante y heterogénea en lo económico, social, patrimonial, histórico y medioambiental. Su entorno ha cambiado enormemente a lo largo de sus siglos de existencia. Es por lo mismo que en algunas partes sus cualidades y valores no son tan evidentes y es, no solo deseable sino necesaria, su puesta en valor y reactivación.

En noviembre de 2020 se celebró el simposio-taller Internacional La Ciudad y el Paisaje Urbano: La Regeneración de un Territorio, que tuvo como objeto de estudio a un tramo de la antigua Calzada México-Tacuba (la sección comprendida dentro de la alcaldía Miguel Hidalgo), con el auspicio de la Unesco, la Universidad del Claustro de Sor Juana y la alcaldía Miguel Hidalgo. Durante este acto académico, se contó con la participación magistral de diversos ponentes nacionales e internacionales que debatieron en torno a diversos aspectos del paisaje urbano histórico desde el punto de vista conceptual, pero también analizando ejemplos análogos que pudieran servir de modelo de buenas prácticas en el planteamiento de propuestas concretas en la Calzada.

Este año, 2021, es el marco conmemorativo de los 500 años de la Conquista, valdría la pena no quitar el dedo del renglón y mantener el foco de atención en la antigua Calzada, que es la vía histórica más antigua del país y cuya existencia y relevancia es frecuentemente ignorada. Este antiguo camino ha sido testigo de grandes transformaciones a lo largo de 600 años, desde su pasado prehispánico, virreinal, independiente y moderno, hasta llegar a la realidad contemporánea de una megalópolis latinoamericana enorme y sobrepoblada.

Siempre la regeneración de un objeto de esta escala se plantea como un problema complejo, que involucra una gran cantidad de actores; es, en todos los casos, un gran reto cuya solución se tiene que planear por etapas y metas asequibles, por lo que la existencia de un plan maestro para esta vía, cuyos orígenes se remontan a la segunda mitad del siglo XIV, tendrá impacto no solo a nivel territorial y local, sino nacional. 


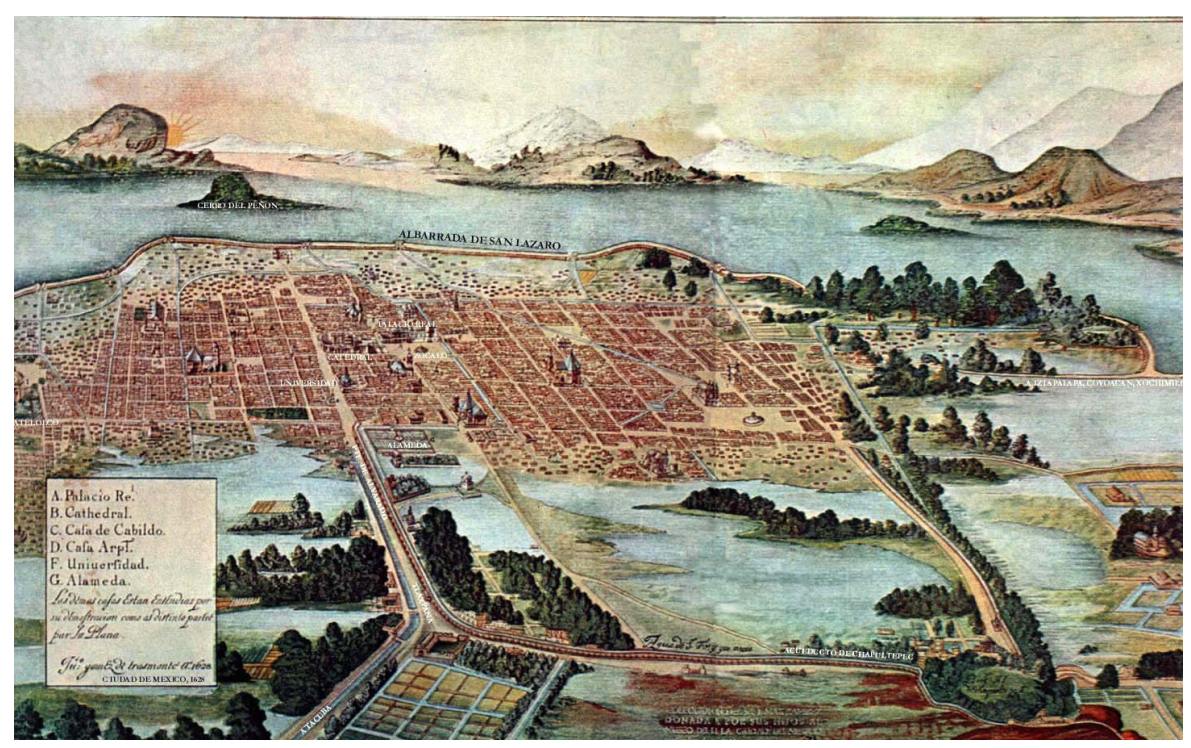

México-Tenochtitlan (frecuentemente solo llamada "Tenochtitlan") es el nombre compuesto que los aztecas o mexicas dieron a su ciudad capital, fundada en 1325. Con el pasar de los años, esta urbe se convertiría en el axis mundi de un poderoso imperio militarizado que abarcaba una gran parte de Mesoamérica.

Al cabo de casi dos siglos, los mexicas, originalmente asentados en un pequeño islote al poniente del gran lago de Texcoco ${ }^{1}$, hicieron crecer físicamente a la ciudad ganando territorio a las aguas salobres que rodeaban a la ciudad por medio de un sistema de jardines flotantes cultivables conocidos como "chinampas", que se convertirían, junto con el comercio y la guerra, en parte del sistema primordial de su economía.

Si bien es cierto que al encontrarse en una isla, México-Tenochtitlan -apodada "la Venecia de América" en el periodo colonial mexicano- se volvió una fortaleza inexpugnable sin muralla, no podía mantenerse aislada en el sentido literal de la palabra. Como una cuestión defensiva, funcionaba bien, pero debía tener conexiones y vías hacia las riberas del lago por razones comerciales y de movilidad.

Con este propósito, y junto con el crecimiento y poblacional y urbano de la ciudad, se crearon cuatro calzadas sobre el agua, una especie de plataformas segmentadas de tierra compactada que sobresalían pocos metros por encima del nivel de las aguas del lago. Dichos tramos eran unidos por tablones que se colocaban de día para darle continuidad y se quitaban de noche para aislar a la ciudad, a manera de "puentes levadizos". Estas calzadas estaban orientadas hacia los puntos cardinales, y de todas, la primera que se construyó hacia el poniente fue la de México-Tacuba, para unir a la ciudad
La Ciudad de México en el siglo XVII con la Calzada México-Tacuba en primer plano. Plano de Juan Gómez de Trasmonte, 1628 | fuente wikimedia

$$
1
$$

El Lago de Texcoco formaba parte de un sistema de cinco lagos que conformaron una cuenca hidráulica conocida hasta la fecha como Valle de México. 


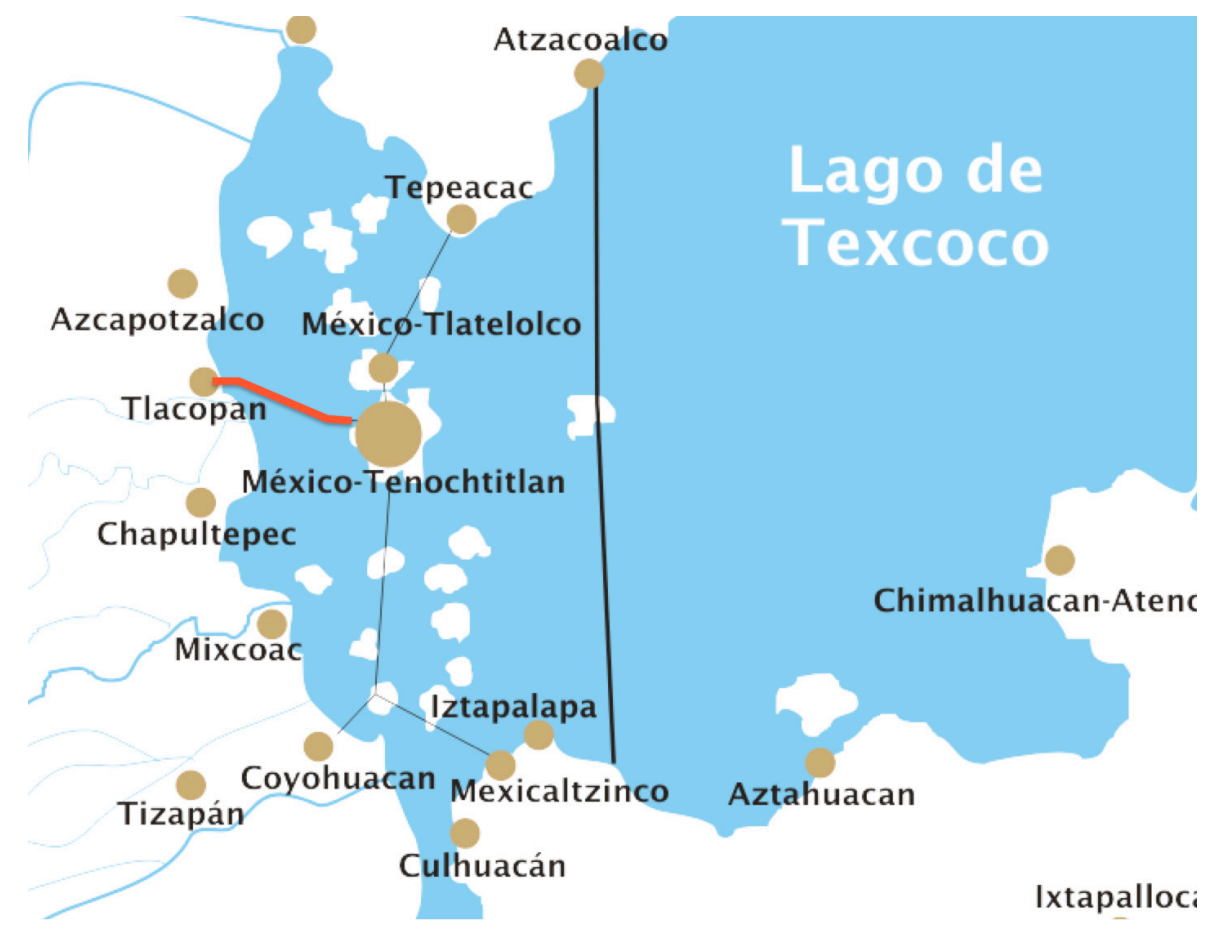

En rojo vemos la ubicación de la antigua calzada comunicando México-Tenochtitlan con Tacuba (época prehispánica)

\section{2}

En el nombre de la Calzada, la palabra "México" hace referencia a la ciudad, no al país, que tomó el nombre de la ciudad hasta el siglo XIX al volverse independiente de España.

3

Este eje en el sentido oriente-poniente llamado "Triple Alianza" unía a las tres "T": Tenochtitlan, Texcoco y Tacuba, y generaba un sistema lacustre perfectamente organizado.

mexica con el antiguo pueblo ribereño de Tlacopan (término castellanizado como "Tacuba"), que se había conformado como un señorío aliado de los mexicas $^{2}$. Hacia el norte se haría la Calzada al Tepeyac (lugar mejor conocido por haber sido, según la tradición, el sitio de las apariciones de la Virgen de Guadalupe en 1521); hacia el sur, la Calzada de Iztapalapa-Coyoacán, y hacia el oriente, la misma calzada México-Tacuba se continuaba hacia un embarcadero, que llevaba por agua a la tierra firme, donde se encontraba la ciudad Texcoco, también aliada de los mexicas ${ }^{3}$. En la confluencia de estas cuatro vías, estaba el corazón religioso y simbólico de México-Tenochtitlan, su recinto ceremonial donde se encontraba el Templo Mayor, cuyos vestigios aún son visibles en el centro histórico de la Ciudad de México.

Dada su particular situación, con la creación de estas calzadas y sus ramificaciones que llevaban al centro de la ciudad agua potable de los manantiales de los alrededores, México-Tenochtitlan se convertiría en una "ciudad anfibia", cuya imagen perduraría por varios años; incluso, después de la llegada de los españoles a este territorio en el siglo XVI, momento a partir del cual se comenzaría un lento pero sistemático proceso de la desecación de las poco profundas aguas de los lagos y el lento crecimiento de la ciudad sobre todo hacia el poniente y hacia el sur.

En 1520, por la Calzada México-Tacuba, se llevó a cabo el pasaje llamado "la Noche Triste", cuando el conquistador Hernán Cortés y sus hombres, acom- 
pañados por una gran cantidad de indígenas aliados, cargados de oro, intentaban escapar secretamente de México-Tenochtitlan, debajo de una oscura noche lluviosa. Habiendo sido descubiertos por los mexicas, estos los atacaron por tierra y por agua y se verificó una sangrienta y mortífera batalla en la cual Hernán Cortés salvó la vida, hasta llegar, continuando por la Calzada hacia el poniente, a las puertas de Tacuba, donde se dice que lloró su derrota a los pies de un árbol, cuyos restos aún existen en el rumbo de Popotla y que se conoce como "Árbol de la Noche Triste". Un año más tarde, en 1521, y después de un sitio de ocho meses, México-Tenochtitlan sería vencida por los españoles y sus aliados indígenas y comenzaría su era hispana bajo el nombre de "Ciudad de México", capital del virreinato de la Nueva España, existente entre 1535 y 1821.

En los siglos virreinales, la antigua Calzada México-Tacuba era ya un camino terrestre tras la desecación de esa porción del lago, al poniente de la Ciudad de México, pero seguía uniendo a la ciudad con el pueblo de Tacuba, sitio en el que sobre ruinas prehispánicas se edificaría la gran parroquia conventual de San Gabriel Arcángel, fundación franciscana del siglo XVI existente hasta al día de hoy. En esta misma época, a lo largo de un tramo de la antigua calzada y como punto intermedio entre la Ciudad de México y Tacuba, se estableció el hospital y convento franciscano de los Santos Cosme y Damián, cuyo rumbo, conocido como San Cosme, se convertiría por muchos años en un enclave preferido por la aristocracia local para la construcción de grandes casas campestres con huertas ${ }^{4}$.

Entre los siglos XVI y XIX, corrió por la calzada un acueducto soportado por una estructura de arcos de mampostería que llevaba agua potable al centro de la Ciudad de México desde manantiales en los alrededores, convirtiendo a esa zona en un punto agradable y codiciado por su alta productividad agrícola y ganadera. Este acueducto se conoció como "de Santa Fe" o "de la Verónica, y de sus 900 arcos, hoy no queda ninguno. Ya en el siglo XIX, a su alrededor, se crearon primeros fraccionamientos "suburbanos" de la Ciudad de México, los mismos que hoy se encuentran completamente insertos en la mancha urbana: San Rafael y Santa María la Ribera. Estos barrios -llamados "colonias" en el contexto mexicano- abrieron el crecimiento de la Ciudad de México y su voracidad constructiva hacia el poniente. En esta área, subsisten pocos ejemplos de arquitectura colonial y tan solo perduran algunas casonas y edificios de apartamentos construidos a finales del siglo XIX e inicios del siglo XX, bajo el impulso modernizador del gobierno de Porfirio Díaz ${ }^{5}$.

Tranvías y vehículos automotores cambiaron el paisaje de la zona, y por el lugar exacto por donde corría el antes mencionado acueducto de la Verónica, hoy corre de manera subterránea la línea del metro que conecta el Centro Histórico con el antiguo pueblo de Tacuba, siguiendo la trayectoria exacta de la antigua Calzada prehispánica.
4

Hoy, por desgracia, quedan muy pocos ejemplos de estas construcciones en medio de un entorno urbano heterogéneo y degradado. Justo en este tramo, la antigua Calzada se llama Ribera de San Cosme.

5

Presidente de México de 1876 a 1880 y de 1884 a 1910 . 


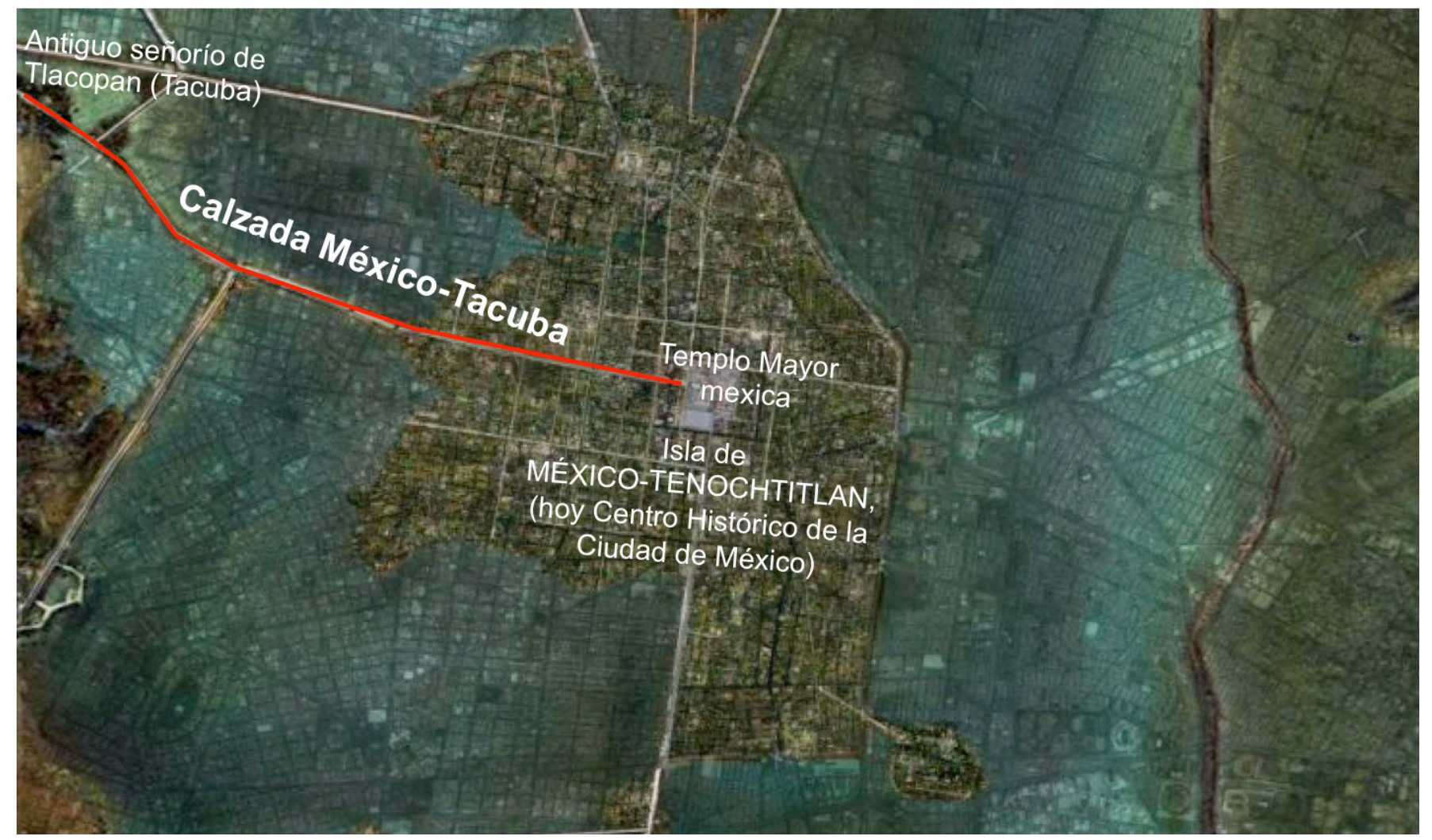

Recreación del islote de México-Tenochtitlan y la su calzada hacia Tacuba. La imagen está sobrepuesta a la traza actual de la Ciudad de México

La falta de regulación del transporte público, estaciones y nodos del metro, han ocasionado la proliferación en la zona de paraderos clandestinos de autobuses y la presencia de un sólido comercio informal, alimentado por la presencia de grandes masas de miles de personas que cruzan el área diariamente. Esta realidad, en cuanto a movilidad en una megalópolis sobrepoblada como lo es la Ciudad de México, puede resultar verdaderamente abrumadora y complicada, situación incomprensible quizá en contextos europeos, en donde la comunicación entre barrios, ciudades e incluso países, no representa una barrera difícil de vencer, y la escala de todos los elementos resulta más manejable.

Volvamos a la situación de la antigua Calzada en su porción incluida en el Centro Histórico de la Ciudad de México, declarado Patrimonio Mundial por la Unesco en 1987. Esta zona tiene el mayor grado de protección en todos los sentidos. Las actuales calles República de Guatemala, Tacuba, Avenida Hidalgo y parte de Puente de Alvarado, nombres que, como se mencionó, son los que bautizan a los primeros fragmentos de la Calzada, quedan dentro de esta zona de monumentos históricos y artísticos, área protegida y regulada, además de por la Unesco, por las autoridades federales mediante dos institutos pertenecientes a la Secretaría (Ministerio) de 
Cultura: el Instituto Nacional de Antropología e Historia (INAH), y el Instituto Nacional de Bellas Artes y Literatura (INBAL). A esto, sumemos la participación del Gobierno de la Ciudad de México a través de las oficinas de la Autoridad y del Fideicomiso del Centro Histórico de la Ciudad de México, de la SEDUVI, y de la alcaldía Cuauhtémoc. Con esto, vemos el esfuerzo de actores involucrados en la conservación del área, al que se suman la participación activa de fundaciones, de la sociedad civil, comerciantes, hoteleros, y turistas nacionales y extranjeros. En los últimos años, esto ha significado una importante derrama económica y el consecuente mejoramiento para los usuarios y habitantes del centro histórico.

No ocurre lo mismo en el tramo de la antigua Calzada comprendido entre las avenidas Guerrero (límite poniente del centro histórico) y Marina Nacional, a $5 \mathrm{~km}$. En esta sección, la antigua vía cruza las colonias Tabacalera, Buenavista, San Rafael y Santa María la Ribera (alcaldía Cuauhtémoc); así como Agricultura, Tlaxpana, Anáhuac, Popotla y Tacuba (alcaldía Miguel Hidalgo). En todo este recorrido existe solamente un pequeño parque sobre la Calzada, Cañitas, y unos diez sitios históricos y patrimoniales de alta relevancia y muy reconocidos ${ }^{6}$, pero que se encuentran aislados y encerrados en sí mismos ante un hostil paisaje urbano. La depredación del entorno natural y cultural en esta parte de la antigua Calzada son alarmantes. No es de extrañarse, por tanto, que la pérdida simbólica de la importancia de la antigua Calzada en el tramo mencionado, donde arquitectura patrimonial llega a ser muy dispersa o nula, vaya de la mano de graves problemas de tránsito, movilidad, comercio informal, inseguridad, y contaminación visual y auditiva.

En ese sentido, la falta de regulación ha provocado que los valores de la Calzada México-Tacuba queden escondidos y que no se pueda interpretar fácilmente como un sistema integrado, comenzando por lo confuso que puede ser el hecho de que tenga seis nombres diferentes a lo largo de su extensión, y que sus cualidades y características sean relacionadas siempre con un tramo en particular y leídas por separado. Parece que, conforme nos alejamos del área declarada como Patrimonio Mundial, los elementos patrimoniales y las áreas verdes de la Calzada presentan una degradación más acusada que es proporcional al deterioro que presenta esta área urbana.

El concepto de paisaje urbano histórico es relativamente nuevo. Pensemos que hace unos años el mayor énfasis estaba volcado en reconocer y declarar monumentos históricos y artísticos, hablando de patrimonio material. Fue un buen avance, y por todo México se reconocieron, incluso varias zonas de monumentos, con una alta concentración de los mismos. Hacia una creciente preocupación acerca del entorno natural del planeta, poco tiempo después se comenzó a concientizar de la importancia del patrimonio natural y su inextricable nexo con el patrimonio cultural, sobre todo tangible.
6

El Museo Nacional de San Carlos, la casa de los Mascarones, la parroquia de los Santos Cosme y Damián, el antiguo cementerio británico-americano, el cine Cosmos, la escuela normal de maestros, el gran colegio militar, la capilla de Merced de las Huertas, el Árbol de la Noche Triste y la parroquia y ex convento de San Gabriel Arcángel, en el centro de Tacuba, junto a la estación del metro del mismo nombre. Parecen no pocos elementos patrimoniales, pero si consideramos que se encuentran a lo largo de $5 \mathrm{~km}$ lineales (prácticamente la mitad de la extensión total de la Calzada), la densidad de los mismos es verdaderamente baja. 

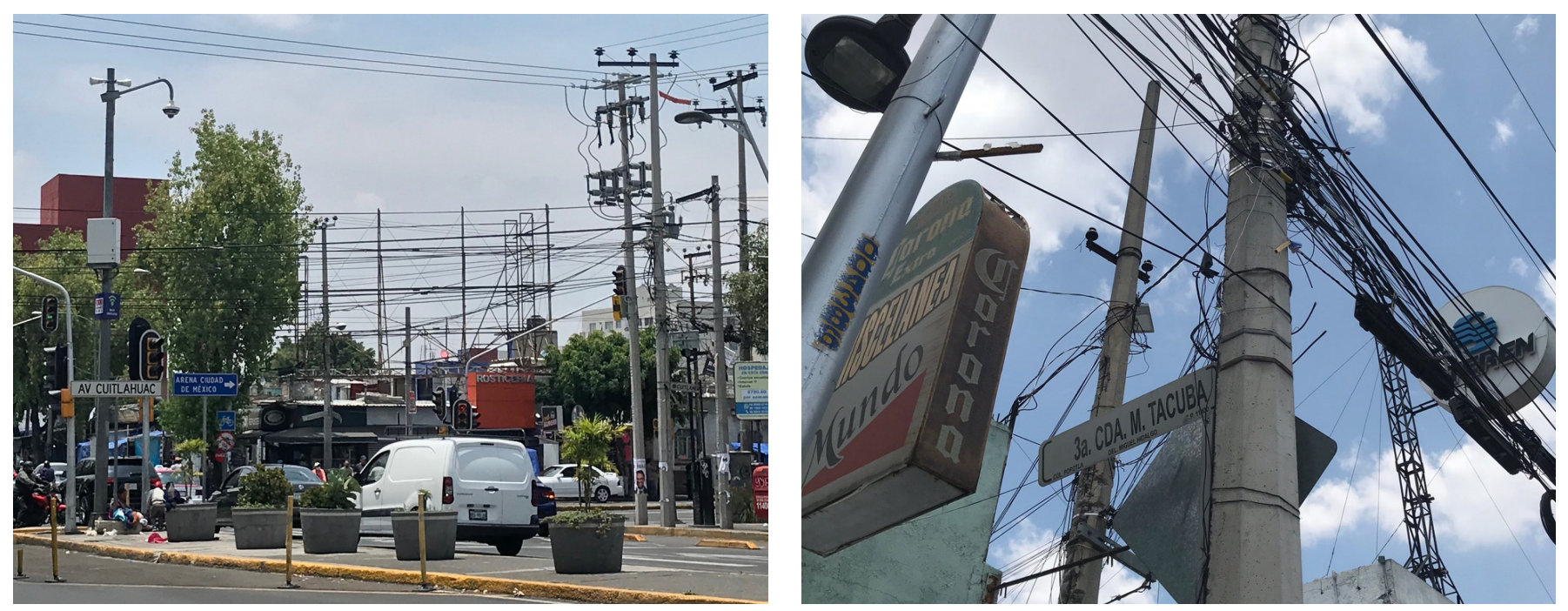

El paisaje urbano luce saturado visualmente, y con un tráfico vehicular constante | fotos Gerardo Hernández Septién

El concepto de patrimonio se enriqueció cuando se amplió a la esfera de lo intangible, y en México se comenzaron a valorar manifestaciones populares y vernáculas como la gastronomía, las fiestas, danzas, trajes típicos, etc.

Estas premisas se han aplicado en ocasiones de modo muy delimitado y hasta cierto punto de manera excluyente. Esto ha sucedido cuando los elementos patrimoniales se han mirado de una manera separada y con límites muy marcados. Por el contrario, el concepto de paisaje urbano histórico se aplica a un determinado contexto que ha sido construido de manera artificial en un entorno natural, idea que rompió con el paradigma de que solo un paisaje natural "intocado" tenía cualidades medioambientales. El concepto de patrimonio urbano histórico ha abierto la posibilidad de un ámbito amplio en el que confluyen los patrimonios culturales tangibles e intangibles, el patrimonio natural y el construido, el arte, la arquitectura, el diseño, el urbanismo, las transformaciones urbanas y las posibilidades que ofrece un sitio en cuanto a su historia como lugar de convivencia, sus aprovechamientos y sus dinámicas urbanas, así como la necesidad de proceder a su regulación visual y acústica. Este concepto implica asimismo temas como los usos del suelo, las políticas de movilidad y las infraestructuras de transporte, las actividades productivas, etc., todo ello con la idea fundamental de la necesidad de contar con un plan de acción que, siendo lo más incluyente posible, nos ayude a valorar, promover y potenciar un área o un lugar que actúe como detonador de desarrollo sostenido y sostenible.

Tendemos a pensar que el pasado es lo valioso, sin darnos cuenta de que todo pasado fue tan presente como lo es este momento, y que las buenas prácticas actuales en el manejo y gestión de un sitio derivarán directamente en la calidad de vida de sus habitantes y usuarios. 


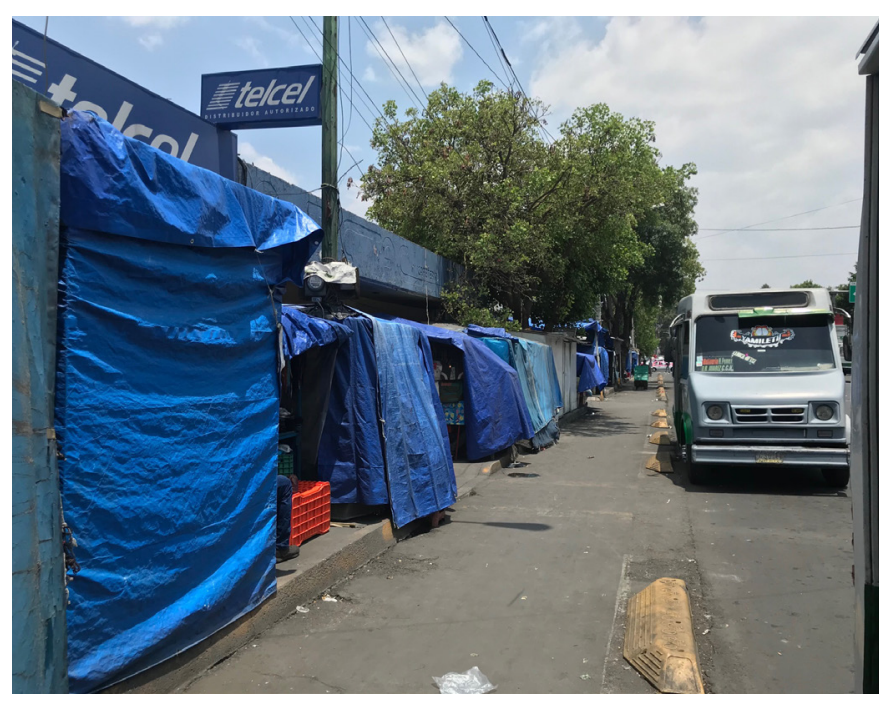

En ese sentido, y volviendo a la Calzada México-Tacuba, el simposio-taller que se organizó en noviembre de 2020 juntó a varios actores en torno a un interesante caso de estudio, como se mencionó. Sin embargo, habría que continuar la inercia ya comenzada, para aterrizar en soluciones concretas que no se queden solo en buenos deseos.

Resulta de total relevancia en un proyecto tan ambicioso como este contar con el apoyo comunitario de la población civil. Este factor tan delicado, "la gente", es parte de ese paisaje y de su realidad diaria, y será el factor definitivo para el éxito o el fracaso de un proyecto. Me refiero a los habitantes y usuarios de la Calzada y sus barrios aledaños, ya que, si no se "vende" la idea de que cualquier mejora realizada en la zona va directamente relacionada con una mayor derrama económica y su impacto directo en la mejora de su calidad de vida, todo esfuerzo será en vano.

Se antoja a momentos abrumador tener en cuenta todas las consideraciones implicadas en un paisaje urbano histórico tan sui generis como la Calzada México-Tacuba, por lo que, en este momento, lo deseable sería retomar el tema, determinar a los actores implicados, continuar viendo ideas y casos análogos surgidos en el marco del simposio-taller (sobre todo en lo tocante al desarrollo de proyectos y gestión de un paisaje urbano histórico con una direccionalidad francamente lineal), y crear un plan maestro rector para la zona, que incluya etapas y metas muy puntuales que aseguren el éxito y la posibilidad de continuar concretando resultados para fases posteriores de manera gradual.

La sostenibilidad no se da solo en el aspecto medioambiental. Junto con la regeneración urbana y natural de la zona se pretende incidir también en la
Ala izquierda, aceras saturadas, sucias y con poco espacio para el peatón junto a las desordenadas estaciones del metro sobre la calzada; a la derecha, el vandalismo y poco cuidado por la arquitectura patrimonial en la zona son una constante | fotos Gerardo Hernández Septién 
Sobre la calzada, se encuentra el Árbol de la Noche Triste, donde según la tradición Hernán Cortés lloró su derrota a manos de los mexicas en 1520 | foto Gerardo Hernández Septién

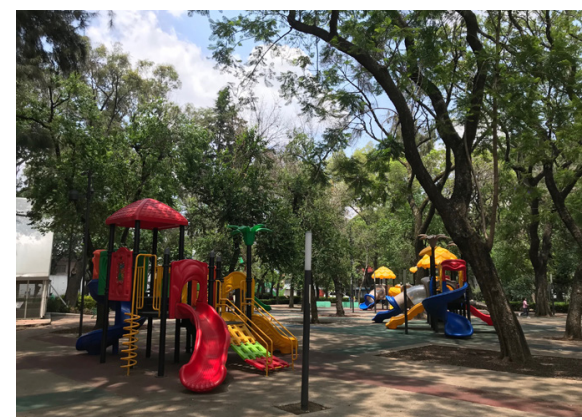

El parque Cañitas es el único pulmón verde en todo el recorrido de la calzada, además de la alameda central, parque monumental ubicado en el centro histórico de la Ciudad de México, a varios kilómetros al oriente | foto Gerardo Hernández Septién

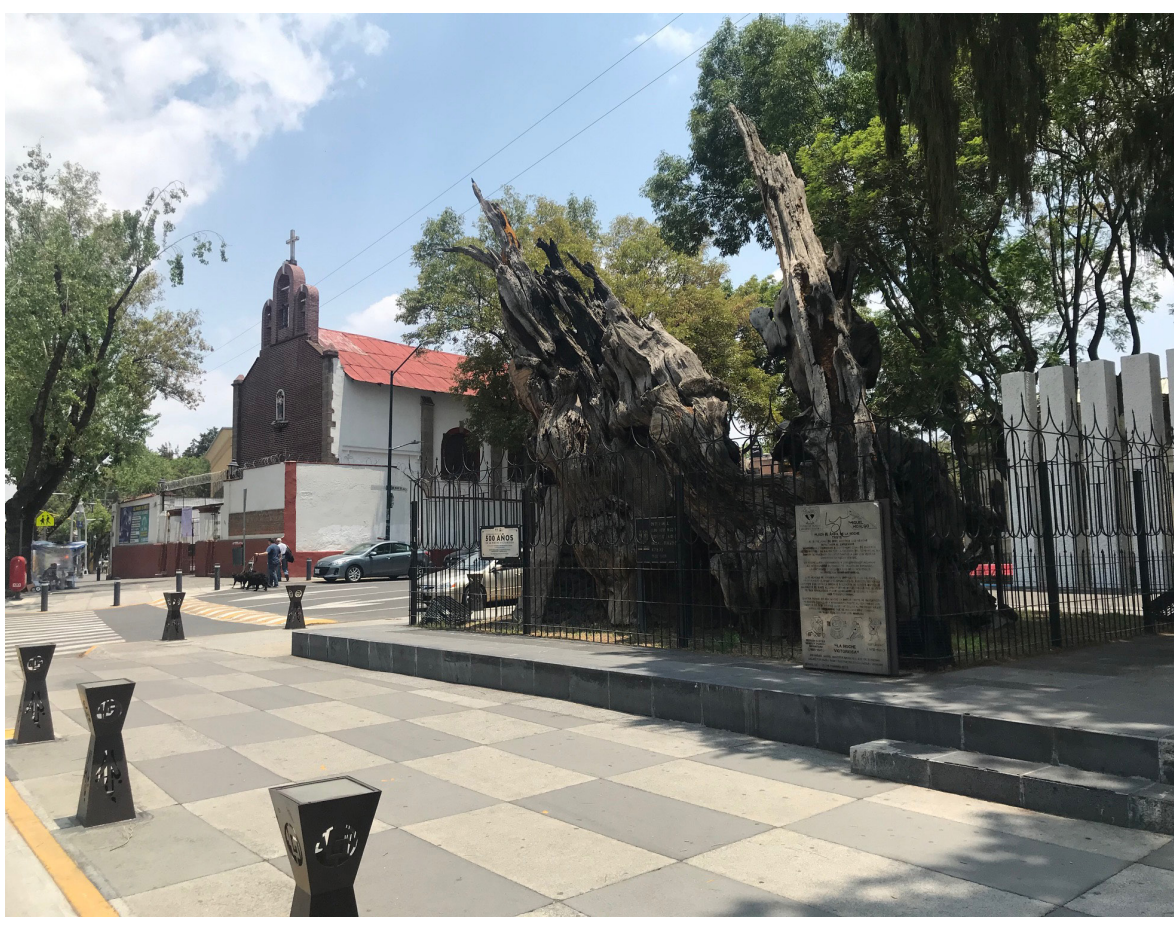

regeneración de tejido social para que un proyecto pueda ser sostenible en varios aspectos.

Una de las primeras acciones necesarias es hacer evidente lo que no lo es, y crear un proyecto de señalética e interpretación histórica en todo el recorrido de la Calzada en espacios públicos que permita su comprensión como sistema y como paisaje urbano-histórico, es decir, que se pueda ver como un sistema completo por primera vez. Esto sacará a la luz su valor bajo la premisa de que "nadie puede conservar lo que no sabe que existe". Habrá, sin embargo, que crear las condiciones que aseguren que la gente quiera ir y que pueda hacer este recorrido de manera placentera y segura (urge reforzar las medidas de seguridad en la zona), desde el centro histórico hasta Tacuba, unificando criterios de diseño urbano por etapas: iluminación, cableado subterráneo, colocación de arbolado y vegetación, mobiliario, pavimentos, etc., en las zonas en donde se carece de una regulación efectiva y aplicable.

También por etapas, habría que crear políticas para la regulación del comercio informal desmedido, que en la actualidad provoca una gran cantidad de basura y de contaminación visual y auditiva; ello ligado a acciones que garanticen la inclusión social en el espacio y su accesibilidad. A la par, hay que concretar acciones para el ordenamiento vial que frecuentemente es un obstáculo y un factor de alta contaminación ambiental en la zona, creando 


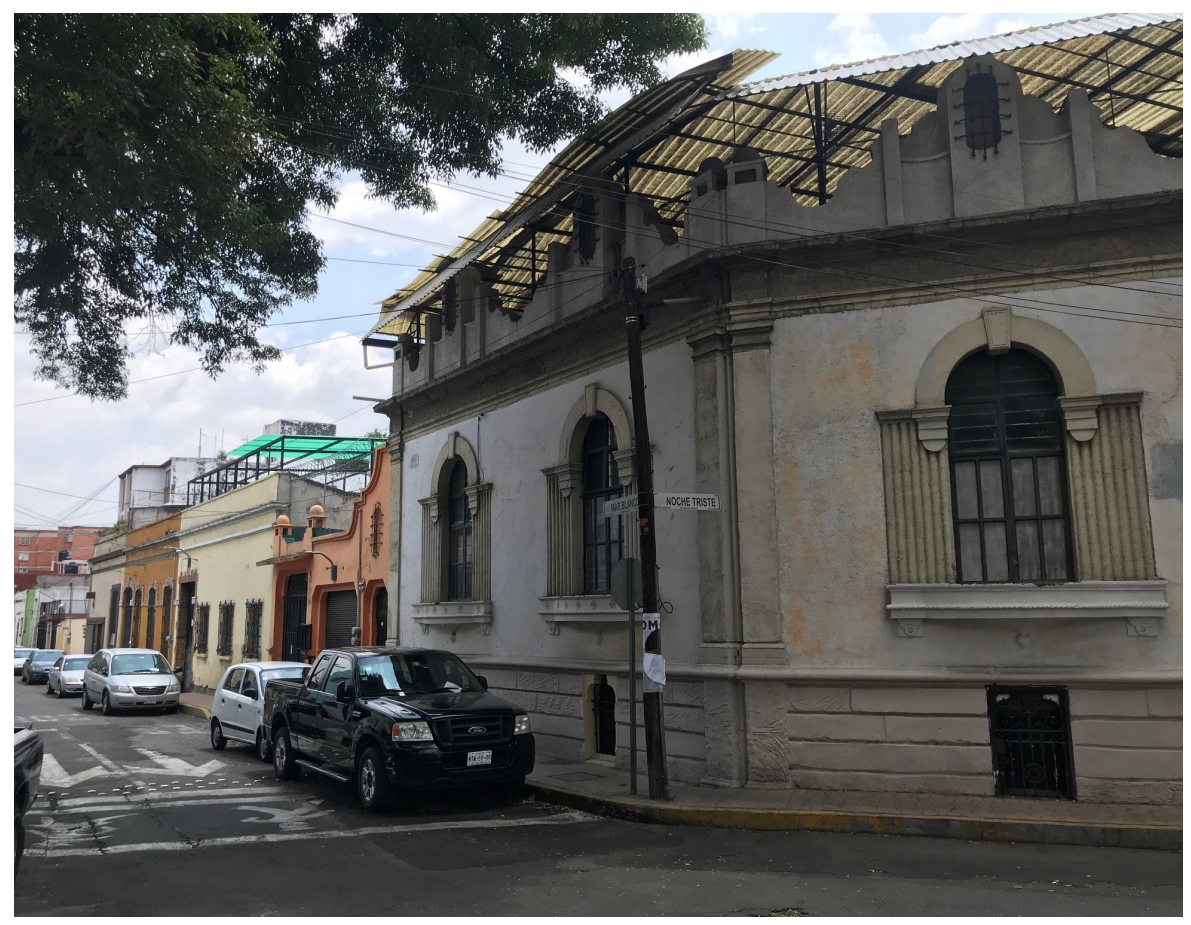

posibilidades para los peatones y ciclistas. Cada vez se pone más el foco Al sur de la calzada, el barrio de Popotla conserva algunos rincones característicos de la arquitectura de inicios del siglo XX en la zona | foto Gerardo en zonas patrimoniales en contextos urbanos como bienes sociales y colecHernández Septién 